\title{
Mulheres no jornalismo esportivo brasileiro: uma análise da atuação profissional sob o olhar do mercado de trabalho ${ }^{1}$
}

\author{
Mujeres en el periodismo deportivo brasileño: un \\ análisis de la práctica profesional desde la perspectiva \\ del mercado laboral
}

\section{Women in Brazilian sports journalism: an analysis of professional performance from the perspective of the job market}

\author{
Érika Alfaro de Araújo ${ }^{2}$ \\ Universidade Estadual Paulista (Brasil) \\ eriikaalfaro@gmail.com \\ Mauro de Souza Ventura ${ }^{3}$ \\ Universidade Estadual Paulista (Brasil) \\ mauroventura@faac.unesp.br
}

Fecha de recepción: 12 de agosto de 2019

Fecha de recepción evaluador: 20 de agosto de 2019

Fecha de recepción corrección: 30 de agosto 2019

\footnotetext{
${ }^{1}$ Este trabalho é parte de monografia apresentada como Trabalho de Conclusão do Curso de Jornalismo, em janeiro de 2018.

${ }^{2}$ Érika Alfaro de Araújo é jornalista e mestranda do Programa de Pós-Graduação em Comunicação da Universidade Estadual Paulista (UNESP). https://orcid.org/0000-0001-6283-9328

${ }^{3}$ Mauro de Souza Ventura é jornalista, Livre-docente em Jornalismo e professor do Departamento de Comunicação Social e do Programa de Pós-Graduação em Comunicação da Universidade Estadual Paulista (UNESP). https://orcid.org/0000-0002-5557-228X
} 


\title{
Resumo
}

Com o objetivo de estudar a atuação de mulheres no jornalismo esportivo brasileiro, foram realizadas entrevistas com profissionais que compõem o mercado de trabalho da televisão aberta, dado o recorte, proposto pela pesquisa, dos programas Jogo Aberto, da Bandeirantes, e Globo Esporte São Paulo, da Rede Globo. A partir da coleta de dados de seis entrevistados, quatro categorias foram desenvolvidas: a relação mulher atleta e mulher jornalista; a atual situação feminina na televisão aberta; a estética feminina e o exercício da profissão; e as diferentes concepções sobre o machismo. Sendo assim, cada aspecto foi analisado levando em conta a opinião e as experiências dos jornalistas entrevistados sob a luz de teóricos que discutem esporte, gênero e jornalismo.

Palavras-chave: mulheres jornalistas, jornalismo esportivo, Globo Esporte, Jogo Aberto, gênero.

\section{Resumen}

Para estudiar la participación de las mujeres en el periodismo deportivo, fueron realizadas entrevistas con profesionales que componen el mercado laboral de televisión abierta brasileña, dado el recorte propuesto por la investigación de los programas Jogo Aberto, de Bandeirantes, y Globo Esporte São Paulo, de Rede Globo. Del contenido de las entrevistas, se desarrollaron cuatro categorías: la relación atleta mujer y mujer periodista; la situación femenina actual en la televisión abierta; estética femenina y práctica de la profesión; y las diferentes concepciones sobre el machismo. Cada aspecto se analizó teniendo en cuenta la opinión y las experiencias de los periodistas por medio de los teóricos que discuten deporte, género y periodismo.

Palabras clave: mujeres periodistas, periodismo deportivo, Globo Esporte, Jogo Aberto, género.

\begin{abstract}
In order to study women's work in sports journalism, interviews were conducted with professionals which form the open television labour market, given the cut proposed by the research, of the programs Jogo Aberto, from Bandeirantes, and Globo Esporte São Paulo, from Rede Globo. Based on data collected from six respondents, four categories were developed: the connection between female athlete and female journalist; the current female situation on open television; female aesthetics and professional practice; and different conceptions about gender discrimination. Each aspect was analyzed considering the opinion and experiences of journalists in the light of authors who discuss sport, gender and journalism.
\end{abstract}

Keywords: female journalist, sports journalism, Globo Esporte, Jogo Aberto, gender. 


\section{Introdução}

Por se tratar de um fenômeno que engloba aspectos políticos, econômicos, sociais e culturais, o esporte adquiriu, ao longo dos anos, espaço nos estudos de gênero, isso porque, para serem inseridas nesse contexto, as mulheres tiveram que transpor diversos obstáculos. Para entender de que forma esse cenário foi possível, voltamos à Antiguidade, período no qual os Jogos Olímpicos já eram disputados - apenas por homens. Nessas competições, as mulheres não poderiam sequer serem espectadoras da competição. Na Era Moderna, as disputas olímpicas tiveram início em 1896 e contaram, novamente, com a participação exclusiva de homens. Ressaltando-se o fator temporal, temos que, apenas nas Olimpíadas de 2012, em Londres, todas as modalidades possuíam uma representante feminina. Conforme elabora Miragaya (2002), era negado às figuras femininas a atuação em atividades físicas porque pensava-se que a mulher era muito delicada e frágil, tendo que se restringir à vida doméstica e levar um estilo de vida passivo. Já se propagou até mesmo o discurso de que a competição esportiva seria perigosa pelo risco de masculinizar a mulher ou por afetar sua saúde. Assim, no Brasil, houve um período em que a proibição das mulheres praticarem esportes, como o futebol, era regulamentada por lei - decreto de lei 3.199, de 14 de abril de 1941, revogado apenas em 1979.

Ao transpormos tal cenário negações para o jornalismo esportivo, sob a perspectiva da atuação de profissionais mulheres nesse campo, também podemos observar um processo longo de inserção. O jornalismo esportivo surgiu no Brasil na década de 1850 e, um século depois, o campo ainda era dominado por homens no país, com raras representantes femininas até, pelo menos, 1970. No entanto, até os dias de hoje, as barreiras são notáveis.

Por esse motivo, o objetivo do presente trabalho é verificar a presença feminina nos programas esportivos da televisão aberta e entender a forma como os e as profissionais inseridos nesse contexto avaliam a relação entre esporte e gênero. Para isso, os objetos selecionados foram o Jogo Aberto, da Band, e o Globo Esporte São Paulo, da TV Globo, duas atrações de grande relevância, há mais de dez anos no ar, em um veículo tradicional para tal área do jornalismo.

\section{Referencial teórico}

Para analisar os objetos e pensarmos nas relações de gênero no esporte e no jornalismo esportivo, partimos do princípio de que cada espaço ocupado pela mulher no nesse campo profissional tem a capacidade de carregar significados sobre o feminino. Segundo Coakley (2007), jornalistas esportivos são peças-chave nesse processo construtivo do mundo social porque representações do esporte podem influenciar as ideias e crenças que as pessoas usam para definir e dar significado a si mesmas. Sendo assim, devemos separar: produção, reportagem, apresentação e opinião dos programas esportivos. A produção acontece nos bastidores, longe das câmeras. A reportagem é uma atribuição que envolve apurar informações, buscar os elementos das notícias, realizar a montagem do texto, contar histórias, entrevistar personagens, ser o agente da divulgação 
de fatos e entender o assunto como um todo para apresentá-lo, da melhor forma, ao telespectador. Já a apresentação, caracteriza-se pelo indivíduo que simboliza um programa esportivo da televisão em termos de imagem, comanda as ações, chama as reportagens e conduz os conteúdos. Muitas vezes, exige-se dessa pessoa, em questões informativas e de distribuição de temas, uma postura objetiva e imparcial. Por último, a análise é um estilo opinativo. Do comentarista ou da comentarista, espera-se um conhecimento profundo sobre os esportes debatidos para que o público possa entrar em contato com pontos de vista sobre performances individuais ou coletivas, decisões, regras, táticas, estratégias e bastidores do mundo esportivo. E é justamente nessa função que a mulher possui menor atuação, conforme confirmaremos adiante. No entanto, além de saber quais posições ocupam e em que volume, devemos questionar o motivo pelo qual os fenômenos acontecem.

É preciso realmente perguntar-se quais são os mecanismos históricos que são responsáveis pela des-historicização e pela eternização das estruturas da divisão sexual e dos princípios de divisão correspondentes. Colocar o problema nestes termos é marcar um progresso na ordem do conhecimento que pode estar no princípio de um progresso decisivo na ordem da ação. Lembrar que aquilo que, na história, aparece como eterno não é mais que o produto de um trabalho de eternização que compete a instituições interligadas tais como a família, a igreja, a escola, e também, em uma outra ordem, o esporte e o jornalismo (estas noções abstratas sendo simples designações estenográficas de mecanismos complexos, que devem ser analisados em cada caso em sua particularidade histórica) é reinserir na história e, portanto, devolver à ação histórica, a relação entre os sexos que a visão naturalista e essencialista dela arranca (e não, como quiseram me fazer dizer, tentar parar a história e retirar às mulheres seu papel de agentes históricos). (Bourdieu, 2003, p. 5)

Pierre Bourdieu, em A Dominação Masculina (2003), oferece um material valioso para a presente análise. Entre outras contribuições, estão os conceitos como a dominação simbólica e a noção de socialização do biológico e de biologização do social, os quais serão trabalhados posteriormente com maior profundidade. E, a exemplo de Bourdieu, Fairclough, Paiva, Drumont, Gomes, Rocha Ferreira, entre outros autores, foram citados no decorrer da fala dos entrevistados no intuito de articular as noções dos profissionais e dos teóricos para entender de que forma a prática pode se integrar a visão dos autores.

\section{Metodologia}

Para apresentar a visão do mercado de trabalho do jornalismo esportivo na televisão aberta, optamos pelas entrevistas semi-estruturadas com indivíduos que o constituem. Tanto homens, quanto mulheres, tanto aqueles que atuam atrás das câmeras, quanto aqueles à frente delas no Globo Esporte São Paulo e no Jogo Aberto. Os questionários foram preparados a partir de perguntas abertas e perguntas fechadas. As respostas obtidas foram agrupadas em documentos e, sobre elas, foi aplicada a análise de conteúdo, que consiste na organização dos dados a partir de padrões de respostas. Do ponto de vista metodológico, trabalharemos com os referenciais estabelecidos por Bardin (2010). 
Do Globo Esporte São Paulo, os entrevistados foram: Carla Canteras, produtora do Departamento de Esportes da TV Globo de 2001 a 2010 e chefe de reportagem no Departamento de Esportes da TV Globo em São Paulo de 2010 a 2017 - a jornalista foi desligada da função dias após a entrevista; Cássio Barco, repórter da Rede Globo e do Globo Esporte; Cida Santos, editora de texto do Globo Esporte São Paulo desde 2001, e Marco Aurélio Souza, repórter do Globo Esporte São Paulo. No caso do Jogo Aberto, entrevistamos Charles Mills, diretor do programa desde 2014, e fomos até São Paulo, na sede da Bandeirantes, para assistir dos bastidores a um dia da atração e, ao final, conversar com Renata Fan, apresentadora do Jogo Aberto desde 2007. Após a coleta de dados, foi possível estabelecer cinco categorias, que serão vistas a seguir.

\section{Resultados}

\section{a) Mulher atleta e mulher no jornalismo esportivo}

No Globo Esporte São Paulo, à frente das câmeras, na reportagem e na apresentação, as mulheres são minoria - o que não acontece na produção. No Jogo Aberto, segundo Mills (2017, informação escrita), dos 10 profissionais que editam o programa no dia a dia, três são mulheres. Mais três são editoras. Produzindo as matérias, três mulheres em um total de 11 repórteres. Além de Renata Fan, a apresentadora. No programa da Band, percebemos que as mulheres atuam em diversos âmbitos, mas são minoria. No caso de Renata Fan, podemos dizer que a jornalista é a apresentadora de uma atração em que um dos formatos é a mesa-redonda e que a mesma participa da análise, mas que esta não é sua função primordial. Sendo assim, o programa possui apenas comentaristas homens.

Durante as entrevistas, quando os profissionais foram questionados sobre as razões pelas quais as mulheres ainda são minoria na editoria esportiva, uma resposta comum surgiu entre eles: o fato do esporte feminino, das mulheres como atletas, não possuírem uma cultura consolidada na mídia e na sociedade brasileira. Para Fan (2017, informação oral), as mulheres têm condições de ocupar esse espaço que ainda não é ocupado, mas acredita que a experiência como jogador ou jogadora é um ponto a favor de um indivíduo.

A apresentadora do Jogo Aberto também conta o seu caso pessoal, pois sua figura gerou dúvidas no início de sua carreira por suas opiniões sobre esporte. E, quando perguntada sobre sua visão acerca do porquê as mulheres eram subestimadas no passado, Fan também estabeleceu a conexão entre a mulher como atleta e a mulher como jornalista.

Na condição de atleta, o futebol feminino, até hoje, ainda tem muito menos visibilidade, investimento, e não tem a propriedade do futebol masculino. As mulheres não trouxeram uma cultura do campo para dentro das redações ou do jornalismo esportivo. Elas tiveram que fazer isso como eu fiz: sendo torcedoras. Quando você é torcedora, fanática, apaixonada, dedicada ao assunto, você vai criando uma memória esportiva, seus argumentos. Eu sempre fiz isso com os amigos do meu irmão, e eu era considerada uma intrusa (Fan, 2017, informação oral). 
Com tal discurso, Renata também denuncia uma limitação na formação do interesse da mulher. Ao falar que era considerada uma "intrusa" entre os amigos do irmão, mostra, por meio de sua experiência, as barreiras que uma mulher, ou menina, que deseja discutir temas esportivos, enfrenta. Se, ao longo da vida, as pessoas estabelecem suas escolhas por suas afinidades e aproximações com temas e realidades, a mulher deve persistir e se posicionar contra as convenções sociais para formar sua memória esportiva ou para praticar esportes. Para Santos (2017, informação escrita), "ainda existe a ideia de que os homens conhecem melhor o esporte, principalmente o futebol, talvez pelo histórico de meninos jogarem mais futebol que meninas". Mas a profissional ressalta que "esse cenário está mudando, uma vez que as novas gerações de mulheres praticam muito mais o futebol do que as anteriores".

As mulheres têm mesmo mais espaço nessas funções de apresentadoras, produtoras e repórteres. Como comentaristas, acho que entra aquela questão: os homens praticam mais futebol desde a infância, o futebol masculino tem mais patrocínio, apoio e visibilidade do que o feminino. Logo, a ideia geral é que eles entendem mais, já que executaram as jogadas que aparecem nas partidas de futebol e, no geral, os ex-jogadores, que são maioria entre os comentaristas, são mais famosos do que as ex-jogadoras. Logo, rendem mais audiência e credibilidade nos seus comentários (Santos, 2017, informação escrita).

Souza (2017, informação escrita), quando questionado se as mulheres ainda estão buscando combater conceitos pré-estabelecidos na área do jornalismo esportivo como profissionais, apresenta uma visão diferente de Santos em questões da prática feminina, mas encontra as mesmas motivações para a profissional do jornalismo esportivo:

Sobre os conceitos pré-estabelecidos, eles existem porque as mulheres não praticam futebol no nosso país, nem são maioria nos estádios. Acredito que a grande resistência venha daí, o preconceito também. $\mathrm{O}$ homem mais cabeça fechada pensa: 'se elas não jogam e não frequentam estádios, como podem 'entender' do assunto?' (Souza, 2017, informação escrita).

Quando perguntada sobre a pouca presença feminina na frente das câmeras, Canteras afirma:

Porque eu acho que tem menos mulheres que gostam e que entendem de futebol e de esporte. Porque para falar de futebol e de esporte, você tem que entender do que você está falando. (Canteras, 2017, informação oral).

Já na visão de Barco (2017, informação escrita), a posição de comentarista é a mais difícil para uma mulher por conta da maior exposição. O profissional do Globo Esporte afirma que comentaristas homens são alvos de críticas e agressões verbais de torcedores diariamente. "A mulher fica ainda mais exposta por ser mulher e pelo preconceito da população" (Barco, 2017, informação escrita). O profissional acredita que o problema não é o meio, mas o público, fator também citado por Santos em questões de audiência. Souza (2017, informação escrita) também avalia que o público masculino tem dificuldade para aceitar uma mulher comentando futebol. Assim, temos fatores a considerar: a representatividade, uma vez que o público homem deseja ver um homem no programa em que assiste; os conceitos pré-estabelecidos, uma vez que ainda se acredita 
que os esportes devem ser territórios masculinos; e a mulher como uma figura mais vulnerável, uma vez que, se os homens recebem críticas e agressões verbais, as mulheres terão maior exposição. "Eu já passei por situações em que fui mal interpretada, que eu, de repente, tenha errado, não dei a melhor opinião. O problema é que a cobrança, um erro de uma mulher, é um erro que fica muito pesado" (Fan, 2017, informação oral).

Em questões de representatividade e da relação do público com jornalistas homens e mulheres, Santos (2017, informação escrita) considera uma "questão difícil, porque são anos e anos de uma cultura masculina no futebol e é complicado mudar esses padrões". A editora de texto do Globo Esporte afirma que se observa no setor de opinião o domínio masculino e que não lhe vinha à mente o nome de uma mulher que, atualmente, trabalhe como comentarista em jogos de futebol masculino. Na reportagem também tem algumas mulheres; mas o domínio é masculino. "Na produção é o setor que percebo um número maior de mulheres" (Santos, 2017, informação escrita).

Pela pouca presença feminina nos contextos esportivos, por questões que fugiam ao direito de escolha, como foi o caso da citada lei brasileira que proibiu a prática do futebol por mulheres, enraizou-se a ideia de que as mulheres não se relacionam, não gostam e não entendem de assuntos esportivos. Se aplicarmos ao cenário a teoria do sociólogo francês Pierre Bourdieu, perceberemos aquilo que o autor chama de um longo trabalho coletivo de socialização do biológico e de biologização do social (2003). De acordo com o estudioso, esse processo produziu nos corpos e nas mentes a inversão da relação entre causas e efeitos, fazendo ver uma construção social naturalizada.

Transpondo tal ideia para a associação entre o exercício da função atlética e da atividade profissional no jornalismo esportivo, percebemos que o elemento biológico, ser fêmea ou ser macho, foi ligado a execução de papéis sociais determinados no contexto esportivo. Logo, um fator construído socialmente, que é a ideia que afasta a mulher de assuntos esportivos, foi transformado em algo biológico e naturalizado na mente das pessoas, a ponto de acharem "natural" que as mulheres não gostem, ou gostem menos, não pratiquem, ou pratiquem menos, esportes - e, portanto, tenham menos conhecimento sobre o assunto por não terem esse tipo de vivência. Por isso a inversão das causas e efeitos: ao invés de entender o processo histórico de marginalização da mulher e de afastamento da figura feminina do universo esportivo, negando-as, muitas vezes, suas vontades e interesses, a ideia perpetuada é a da naturalidade da falta de aptidão e familiaridade das mulheres com o esporte - segundo essa linha de pensamento, também seria natural que elas demonstrem menos interesse por essa área do jornalismo. Tais análises, que não procuram razões, apenas reproduzem a naturalização do sexismo, contribuem para a manutenção da divisão sexual de espaços, funções e tarefas. Dessa forma, indicam que o sexo pode determinar as escolhas profissionais e pessoais; como se um fator biológico afetasse a evolução e participação social de alguém.

A divisão entre os sexos parece estar "na ordem das coisas", como se diz por vezes para falar do que é normal, natural, a ponto de ser inevitável: ela está presente, ao mesmo tempo, em estado objetivado nas coisas (na casa, por exemplo, cujas partes são todas "sexuadas"), em todo o mundo social e, em estado incorporado, nos corpos e nos 
habitus dos agentes, funcionando como sistemas de esquemas de percepção, de pensamento e de ação (Bourdieu, 2003, p. 17).

Canteras, ex-chefe de produção do GE-SP, acredita que existem menos mulheres que entendem de futebol, principal esporte noticiado pelos programas brasileiros, mas também não consegue identificar as raízes do fato. Por não reconhecer as explicações racionais existentes, Canteras introduz o fator emocional ligado ao esporte.

Eu não tenho uma opinião formada, mas, para mim, eu ligo com paixão, e paixão não tem muita explicação. Então é isso, eu acho que tem mais homens que entendem de esporte e de futebol do que mulheres. Agora, o porquê, não sei (Canteras, 2017, informação oral).

Não só no esporte, nem apenas como jornalistas, mas, no geral, foram negados critérios básicos a mulheres para suas formações profissionais. Estima-se que as primeiras universidades do mundo surgiram por volta de 1088, em Bolonha, na Itália. No entanto, apenas em 1678, a primeira mulher conquistou um diploma no Ensino Superior. Depois, o mercado de trabalho, por ser um ambiente exterior à vida doméstica, também foi negado à mulher. Foi necessário mais uma movimentação de evolução histórica e de esforços feministas para que as mulheres ocupassem esse espaço social. "O fato de o esporte ter emergido de um passado de desigualdades, carregado de valores masculinos, influencia na menor participação das mulheres na prática esportiva" (Rocha Ferreira, 1997).

Dessa forma, observamos que foi comum às respostas dos entrevistados atribuírem a presença feminina na televisão aberta à falta de uma cultura que transfira a experiência da prática esportiva para o comentário de programas jornalísticos. No entanto, apesar de conscientes do domínio masculino, os mesmos não reconhecem ou não denominam as estruturas e discursos que o mantém, além do processo histórico de consolidação e disseminação de preconceitos e privações que afastaram a mulher do contexto esportivo.

Dado que todas as sociedades são delineadas pelo gênero, pelas relações de gênero e pela hierarquia de gênero, e tratando-se o nosso tema de mulheres, fica claro que o que se passa com as mulheres do desporto é reflexo de outros âmbitos sociais, com raízes socioculturais muito profundas (Gomes, 2004, p.17).

\section{b) Uma reflexão sobre as dificuldades femininas em relação à estética}

Partindo de questionamentos sobre padrões de beleza femininos relacionados à televisão, discorreremos sobre tal assunto, uma vez que duas, das três mulheres consultadas, o ressaltaram, mas com opiniões e vivências diferentes. Segundo Canteras:

O erro de muitos canais de televisão é colocar as mulheres bonitas que não entendem 'um ovo' de esporte. Quando você faz reportagem, você tem que entender do que você fala. Quando você apresenta, você tem que ser bonita (Canteras, 2017, informação oral).

Diante de suas colocações, de uma mulher que foi chefe de produção e reportagem durante sete anos no Globo Esporte, percebemos que a profissional acredita que a estética é um ponto considerado pelo mercado de trabalho. Conforme Righi, (2006), a televisão 
descobriu que trazer para frente das câmeras pessoas que refletissem um ideal de beleza na sociedade poderia ser uma forma de atrair mais audiência. Para Baggio (2012), tal cenário reflete um estereótipo ligado ao gênero feminino.

Canteras (2017, informação oral) ainda avalia que esse fator negativo faz muita diferença para as mulheres e que é algo que ainda não mudou com relação ao passado no qual o preconceito sobre o trabalho feminino era tangível e revelado. Assim, a profissional atribui a essa razão um dos fatores pelo qual a mulher ainda encontra dificuldades em ocupar espaços nas telas da televisão aberta. "Quando você está atrás das câmeras, a sua vida é um pouco mais protegida" (Canteras, 2017, informação oral).

Dos homens não se exige tanto: homem pode estar mais gordinho, pode ser mais baixo, pode estar grisalho. E isso é uma prova de que o machismo existe 'pra caramba'. Porque eu acho que a mulher é muito cobrada pela estética. A mulher não pode envelhecer direito (Canteras, 2017, informação oral).

Sob a visão de Canteras, verificamos outra diferença entre o feminino e o masculino: enquanto as posições dos homens como jornalistas conhecedores do tema e atletas profissionais não foram historicamente questionadas, limitadas ou negadas, a aparência dos mesmos não foi um fator que impediu ou foi discutido pelo mercado de trabalho. Para Lipovetsky (2000), a valorização da beleza feminina no contexto profissional atua como uma ferramenta de discriminação sexual.

Em contrapartida, temos a visão de Renata Fan. A gaúcha teve uma trajetória no universo de concursos de beleza antes do jornalismo. Assim, quando iniciou sua carreira na televisão, a questão da aparência era muito presente. Quando questionada sobre esse início na profissão, se era subestimada, se existiam pessoas que duvidavam dela e se já havia passado por situações que a incomodaram, respondeu:

Passei, sim, porque eu comecei como assistente de palco nos programas Terceiro Tempo e Debate Bola, da Record. E eu era a questão figurativa da história, eu entregava os brindes para jogadores, treinadores, para os convidados do programa. Eu era aquela pessoa que fazia uma figuração; como se você tivesse um objeto bonito (Fan, 2017, informação oral).

Renata deixa transparecer que tal situação não a agradava: ser resumida às questões físicas. Por isso, conta que, a cada dia, demonstrava seu conhecimento. Em meio a discussões, tinha respostas prontas porque se preparava. Mesmo assim, as pessoas se perguntavam se a jornalista estava correta nas informações que fornecia, e se surpreendiam quando procuravam pela confirmação e a obtinham. "Eles perceberam que eu não estava ali apenas para servir de mulher bonita" (Fan, 2017, informação oral).

Enquanto Canteras alerta para o fato de que a estética é um fator exigido às mulheres, o que é visto como negativo para muitas, a experiência de Fan revela que esse elemento fez com que ela fosse subestimada no sentido de ser reduzida apenas a ele. Diante desse cenário, revela-se a objetificação feminina e minimização de suas capacidades em duas faces: aquela que exclui o conhecimento da mulher caso seus atributos físicos não sejam considerados adequados e, a segunda, que exclui o 
conhecimento da mulher que possui tal característica, mas é limitada a ela, considerando que os dois pontos (estética e conhecimento) não possam caminhar juntos. Resumidamente, aquelas que não têm o atributo exigido são reduzidas, e aquelas que têm também são. Para Oliveira e Oliveira (2017), os padrões de beleza são definidos por uma cultura que privilegia o olhar masculino. Tanto que Fan (2017, informação oral) afirma ter sofrido pressão por sua aparência em dois aspectos: primeiro, para não parecer tão feminina. Ou seja, para ficar mais semelhante aos jornalistas homens e ao contexto esportivo. Segundo, para que não usasse roupas chamativas, uma vez que os homens seriam distraídos por sua beleza e não prestariam atenção ao conteúdo do programa. "Eu sofri muita pressão para cortar cabelo, para usar tênis. 'Você não pode usar um vestido muito sensual porque os homens vão olhar só para isso"” (Fan, 2017, informação oral).

Dessa forma, a imagem que a apresentadora passava por meio do seu vestuário seria regulada por meio do que o público masculino pensaria ao assisti-la caso a mesma não tivesse resistido.

\section{c) Machismo na profissão}

"O machismo é definido como um sistema de representações simbólicas, que mistifica as relações de exploração, de dominação, de sujeição entre o homem e a mulher" (Drumont, 1980). Tendo em vista tal definição, buscamos verificar se os e as profissionais dos programas analisados percebem a manifestação dessas representações simbólicas em suas áreas de atuação.

Para Souza (2017, informação escrita), repórter do Globo Esporte, não: "se existe machismo ele está fora das redações que eu frequentei e frequento". No entanto, Cássio Barco, que atua na mesma redação, possui uma visão diferente. "Infelizmente, o mundo ainda é machista, e isso reflete na nossa profissão" (Barco, 2017, informação escrita). Já Charles Mills (2017, informação escrita), diretor do Jogo Aberto, afirma não considerar machista o meio do jornalismo esportivo na televisão aberta.

Canteras (2017, informação oral) conta que trabalha há 16 anos com esporte e que já sofreu com o preconceito por ser mulher, mas não na TV Globo. Santos (2017, informação oral), que trabalhava ao lado de Canteras e segue com Barco e Souza no Globo Esporte, diz que acredita que o meio seja machista. Assim como acrescenta Renata Fan: "eu percebo, sim, muito machismo" (FAN, 2017, informação oral).

Dessa forma, diante da visão dos seis entrevistados, percebemos que a unanimidade ao reconhecer o machismo foi feminina. Isso porque, se o fenômeno é composto por um sistema de representações simbólicas, o lugar de fala daquele indivíduo que passa pelos elementos dessa estrutura é mais claro. Sendo assim, apesar de reconhecerem determinadas situações, como o caso de Barco, os homens não entendem de forma profunda episódios pelos quais não passaram.

A visão androcêntrica impõe-se como neutra e não tem necessidade de se enunciar em discursos que visem a legitimá-la. A ordem social funciona como uma imensa máquina simbólica que tende a ratificar a dominação masculina sobre a qual se alicerça: é a divisão social do trabalho, distribuição bastante estrita das atividades atribuídas a cada um dos dois sexos, de seu local, seu momento, seus instrumentos (...) (Bourdieu, 2003, p. 18) 
Ainda assim, a dominação masculina é tamanha e tomou conta de tantos setores da vida social que, em determinados momentos, as próprias mulheres não a reconhecem. Assim, temos, mais uma vez, o que Bourdieu chama de dominação simbólica. Apesar de perceberem situações em que a divisão sexuada do mundo se encarrega de separá-lo entre "coisa de homem" e "coisa de mulher", algumas limitações, por serem veladas, não revelam de forma explicita essa raiz da diferenciação entre os gêneros.

Apesar de afirmar não ter sofrido preconceito na TV Globo, ao ser questionada se já havia passado por outra situação incômoda por ser mulher, Canteras (2017, informação oral) afirma que se trata de um ambiente extremamente masculino, então, as coisas e as piadas que se ouvem são machistas. Além disso, a jornalista ainda afirma: "Eu acho que trabalhar com esporte e trabalhar com uma quantidade maior de homens do que de mulheres, em determinados momentos, faz com que a gente fique menos 'mimimi'" (Canteras, 2017, informação oral). O termo citado é coloquialmente utilizado nas redes sociais para satirizar, pejorativamente, reclamações, em uma onomatopeia que faz referência ao som de uma pessoa chorando. Com tais colocações, por relacionar o incômodo de uma mulher ao passar uma situação machista ao referido "mimimi”, Carla reduz e banaliza a temática do gênero à mera reclamação ou descontentamento. Além disso, não identifica que piadas machistas, por exemplo, são apenas mecanismos de perpetuação da lógica masculina. A piada ou brincadeira nada mais é do que um discurso e carrega consigo sentidos.

O discurso contribui para a constituição de todas as dimensões da estrutura social que, direta ou indiretamente, o moldam e o restringem: suas próprias normas e convenções, como também relações, identidades e instituições que lhe são subjacentes. O discurso é uma prática, não apenas de representação do mundo, mas de significação do mundo, constituindo e construindo o mundo em significado. (Fairclough, 2008, p. 91)

"Grande parte do fluxo discursivo existente na atualidade se torna responsável pela permanência de estruturas sociais nas quais o preconceito e a exclusão consolidamse como regra" (Paiva, 2008). Assim, a autora destaca que, entre os artifícios que propiciam e mantém essas estruturas, estão as piadas, os chistes populares e as anedotas.

\section{d) A atual situação feminina no mercado de trabalho da televisão aberta no jornalismo esportivo}

Percebemos que a questão central nas respostas dos entrevistados é que, para avaliar o presente, o mesmo foi comparado a um passado em que as mulheres não ocupavam esse espaço e não tinham representatividade, ao invés de uma realidade igualitária. Segundo Fan (2017, informação oral), o mercado de trabalho é muito mais fácil agora do quando começou. "E não porque as mulheres não tivessem condições, mas porque elas não tinham espaço; e isso foi acontecendo gradativamente" (Fan, 2017, informação oral).

Quando as mulheres começaram a trabalhar, mostraram sua competência, o quanto elas são profissionais, isso abriu espaço, um novo caminho para todas nós. E, 
quando uma mulher tem sucesso, outra ganha oportunidade, outra vai ter a chance de mostrar algo novo, diferente. (Fan, 2017, informação oral)

Dessa forma, Fan também admite a importância da representatividade, de mulheres que ocupem espaços e demonstrem suas capacidades para que o caminho seja aberto para outras, o que ressalta a importância da presença feminina em contextos antes negados a elas. No entanto, quando questionada se abrir o debate acerca das condições femininas seria benéfico para o mercado de trabalho e para a sociedade, Fan (2017, informação oral) afirma acreditar que não deveríamos ainda estar discutindo se a mulher precisa ou não precisa de espaço. "Na minha opinião isso é algo que já aconteceu, as mulheres têm o seu espaço e é uma tendência natural que elas evoluam" (Fan, 2017, informação oral).

Já Canteras (2017, informação oral) observa que alguns aspectos já mudaram. Segundo a ex-supervisora de reportagem do Globo Esporte, as redações são reflexo da sociedade. Santos (2017, informação escrita) concorda ao considerar que, ao longo dos anos, as mulheres ganharam mais espaço nas redações. No mesmo sentido, Mills (2017, informação escrita) avalia que o espaço para as mulheres em programas esportivos é cada vez maior. Souza (2017, informação escrita) também pondera que começou a trabalhar em 2000, e o número de mulheres nas redações desde então aumentou.

O diretor do Jogo Aberto também oferece os dados da atração. Conforme Mills (2017, informação escrita), dos 10 profissionais que editam o programa no dia a dia, três são mulheres (30\%). Nas ruas, produzindo as matérias, ainda de acordo com o profissional, são 11 repórteres, dos quais três são mulheres (aproximadamente 27,2\%). Renata Fan, a apresentadora, ocupa sozinha essa posição e, nos debates, é a única mulher entre uma quantidade variável de comentaristas - de três a cinco por programa - mas, sempre, todos eles homens. Além disso, observamos durante a visita ao programa, que, no estúdio, além de Renata, havia apenas outras duas mulheres, que eram sua maquiadora e cabelereira. Os câmeras e produtores presentes no local em que o programa é transmitido são todos homens. No Globo Esporte São Paulo, os dados baseados nos créditos $^{4}$ exibidos ao final da atração mostram 35 profissionais, dos quais apenas quatro são mulheres $(11,4 \%)$. A posição única de apresentador era de Ivan Moré. De comentaristas, Caio Ribeiro e Walter Casagrande. E, conforme Barcos (2017, informação oral), são 10 repórteres do esporte da TV Globo em São Paulo, e só uma mulher, a Camila Silva. Tal cenário reflete em $10 \%$ de presença feminina.

Por isso, consideramos que dizer que as mulheres já possuem o seu espaço consolidado configura-se como uma visão simplista, uma vez que o esporte como um todo, o futebol e o jornalismo esportivo se desenvolveram em um passado de desigualdades de gêneros e carregam essa característica até hoje. Apesar das conquistas femininas existirem, ainda são poucas. Além disso, os entrevistados apresentaram

\footnotetext{
${ }^{4}$ Informações de créditos do programa foram levantadas por meio da plataforma Globo Play. Disponível em: <https://globoplay.globo.com/v/6322591/programa/> e <https://globoplay.globo.com/v/6333205/programa/>. Acesso em 11 de agosto de 2019.
} 
divergências ao serem questionados se as mulheres ainda estão buscando combater conceitos pré-estabelecidos e se firmar na área do jornalismo esportivo. Mills (2017, informação escrita) acredita que sim e que estão atingindo esse objetivo. Santos (2017, informação escrita) concorda, acrescentando que se trata de um mundo com domínio masculino e que ainda se tem muita luta pela frente. Para Barcos (2017, informação escrita), essa premissa é verdadeira não só no contexto esportivo como em todas as outras áreas. Já Canteras (2017, informação oral) acredita que não, uma vez que as mulheres já estão estabelecidas em suas funções. "Quando a gente fala que a mulher precisa se firmar é um papel de coitadinha". (Canteras, 2017, informação oral). Analisamos que a leitura de Canteras sobre a situação desconsidera o cenário atual em que a mulher é minoria, além de diminuir a denúncia do machismo e da investigação social ao colocar o tema sob o prisma da mulher em um "papel de coitadinha". Avaliamos também que divulgar a circunstância em que mulher está inserida no mercado de trabalho é de extrema relevância, uma vez que, para que um cenário negativo seja mudado, ele precisa ser identificado. E o fato de uma mulher não identificar tal necessidade evidencia a ação da violência simbólica proposta por Bourdieu.

O efeito da dominação simbólica (seja ela de etnia, de gênero, de cultura, de língua etc.) se exerce não na lógica pura das consciências cognoscentes, mas através dos esquemas de percepção, de avaliação e de ação que são constitutivos dos habitus e que fundamentam, aquém das decisões da consciência e dos controles da vontade, uma relação de conhecimento profundamente obscura a ela mesma. (Bourdieu, 2003, p. 49)

Ao afirmar que existem profissionais firmadas em suas posições, Canteras leva em conta casos individuais, e não coletivos. Fan (2017, informação oral) também acrescenta que ainda não há registros de uma mulher chefiando um departamento de esportes em televisão, o que mostra mais um lugar ainda não conquistado pelas mulheres. Sendo assim, se as figuras femininas não são maioria em nenhuma função, não chefiam departamentos esportivos na televisão e ainda sofrem com o machismo, concluímos que elas ainda estão buscando consolidação nessa área.

\section{Discussões e conclusões}

Diante da proposta de analisar as falas dos entrevistados para entender a visão do mercado de trabalho a respeito da inserção feminina no jornalismo esportivo, foi possível chegar a algumas conclusões, tendo em vista que o conteúdo pôde oferecer diferentes perspectivas sobre o dia a dia no jornalismo esportivo das emissoras. Assim, ao compilarmos as falas dos seis profissionais, percebemos temas em comum e analisamos, levando em conta autores importantes, como Pierre Bourdieu, os que se destacaram: machismo, questões de estética, a relação entre a prática esportiva e o exercício jornalístico, além da leitura do presente baseada no passado foram tópicos abordados. Sobre o machismo, percebemos que o fenômeno existe, e que ele é, muitas vezes, mascarado, por isso os homens que não o vivenciam não o percebem, e as mulheres preferem criar mecanismos de defesa para que esse tema não seja o foco de suas carreiras. $\mathrm{O}$ assunto beleza das jornalistas denuncia a forma como as mulheres estão cercadas de 
restrições por todos os lados: enquanto aquelas que se encaixam em padrões de beleza da sociedade são subestimadas e têm suas competências colocadas em dúvida, aquelas que não preenchem requisitos estéticos exigidos são deixadas de lado. Já para os homens, tais noções não são aplicadas, demonstrando a diferenciação baseada no gênero e mais uma barreira imposta à mulher. Para os entrevistados, a posição atual da mulher é muito melhor com relação ao passado. E neste ponto detectamos uma problemática: em tempos mais antigos, as mulheres simplesmente não ocupavam espaço no jornalismo esportivo, então, qualquer participação seria positiva se relacionarmos ao passado. Assim, sua atuação minoritária deve ser investigada e melhorada. Além disso, quando os entrevistados foram questionados sobre os motivos pelos quais as mulheres eram deixadas de fora do universo esportivo pelo simples fato de serem mulheres, os profissionais demonstraram não entender as raízes históricas da dominação masculina e a importância de se discutir tais fatos para que tal cenário, de fato, possa ser transformado.

\section{Referências bibliográficas}

Baggio, L. M. (2012). Representação da mulher no telejornalismo esportivo: a atuação da jornalista Renata Fan no programa Jogo Aberto da TV Bandeirantes. Rio Grande do Sul.

Bardin, L. (2010). Análise de conteúdo. Lisboa: Edições 70.

Bourdieu, P. A (2003). Dominação Masculina. Rio de Janeiro: Bertrand Brasil.

Coakley, J. (2007). Sports in Society: Issues and Controversies. New York: McGrawHill.

Drumont, M. P. (1980). Elementos para uma análise do machismo. Perspectivas: Revista de Ciências Sociais, v. 3. Recuperado de: 〈http://hdl.handle.net/11449/108171〉.

Fairclough, N. (2008). Discurso e mudança social. Brasília: Editora UnB.

Gomes, P. B. (2004). Mulheres e desporto: qual a agenda pedagógica do século XXI? In: III Fórum de debates sobre mulher \& esporte - mitos e verdades. Universidade de São Paulo-USP.

Lipovetsky, G. (2000). A terceira mulher: permanência e revolução do feminino. São Paulo: Companhia das Letras.

Miragaya, A. (2002). A mulher olímpica: tradição versus inovação na busca pela inclusão. Fórum Olímpico. Rio de Janeiro.

Oliveira, A. P.; Oliveira, N. L. A mulher no jornalismo esportivo. Revista Observatório, [S.1.], v. 3, n. 5, 2017. Recuperado de:

<https://sistemas.uft.edu.br/periodicos/index.php/observatorio/article/view/3326 $>$. 
Paiva, R. (2008). Política: palavra feminina. Rio de Janeiro: Mauad X.

Righi, A. F. (2006). As Donas da Bola - Inserção e Atuação das Mulheres no Jornalismo Esportivo Televisivo. Santa Maria/RS: Comunicação Social/Centro Universitário Franciscano, Recuperado de

<http://lapecjor.files.wordpress.com/2011/04/anelise-righi.pdf>.

Rocha Ferreira, M. B. (1997). A mulher e esporte: uma abordagem históricaantropológica. In: V Encontro de História do esporte, lazer e Educação Física. Coletânea. Maceió.

\section{Fonte online}

Legislação Informatizada - DECRETO-LEI No 3.199, DE 14 DE ABRIL DE 1941 Publicação Original. <http://www2.camara.leg.br/legin/fed/declei/19401949/decreto-lei-3199-14-abril-1941-413238-publicacaooriginal-1-pe.html>. 